\title{
Publisher Correction: Orexin signaling modulates synchronized excitation in the sublaterodorsal tegmental nucleus to stabilize REM sleep
}

Hui Feng, Si-Yi Wen, Qi-Cheng Qiao, Yu-Jie Pang, Sheng-Yun Wang, Hao-Yi Li, Jiao Cai, Kai-Xuan Zhang, Jing Chen, Zhi-An Hu, Fen-Lan Luo, Guan-Zhong Wang, Nian Yang \& Jun Zhang

Correction to: Nature Communications https://doi.org/10.1038/s41467-020-17401-3, published online 21 July 2020.

In the original version of this Article, the captions of Figs. $6 \mathrm{i}, 7 \mathrm{f}$, and $8 \mathrm{j}$ were inadvertently changed during the production process from 'EEG theta power' to 'EMG theta power'. In addition, in Fig. 7c, the separated left captions 'EMG' and 'Frequency (Hz)' were inadvertently merged as a single term during the production process. They have now been separated more clearly to label the raw data and frequency plot separately. The Peer Review File was also formatted incorrectly. This has now been corrected in the PDF and HTML versions of the Article.

Published online: 25 September 2020

\footnotetext{
(c) (i) Open Access This article is licensed under a Creative Commons Attribution 4.0 International License, which permits use, sharing, adaptation, distribution and reproduction in any medium or format, as long as you give appropriate credit to the original author(s) and the source, provide a link to the Creative Commons license, and indicate if changes were made. The images or other third party material in this article are included in the article's Creative Commons license, unless indicated otherwise in a credit line to the material. If material is not included in the article's Creative Commons license and your intended use is not permitted by statutory regulation or exceeds the permitted use, you will need to obtain permission directly from the copyright holder. To view a copy of this license, visit http://creativecommons.org/licenses/by/4.0/.
}

(C) The Author(s) 2020 